\title{
INTRODUCTION
}

\section{Why Ritual in Its Own Right? How So?}

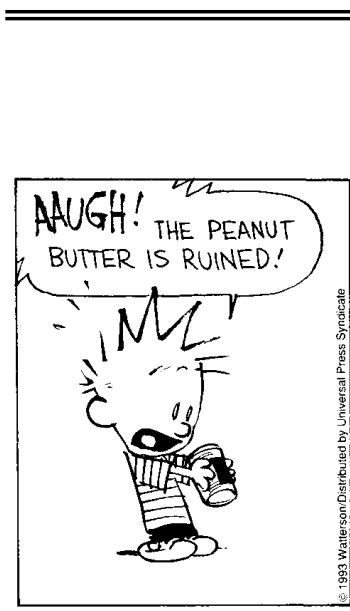

YOU'RE SUPPOSED TO SCOOP ONE HALF STRAIGHT DOWN AND THEN DIG OUT THE OTHER SIDE FROM THE BOTTOM, SO PART OF THE TOP REMAINS UNDISTURBED UNTIL THE
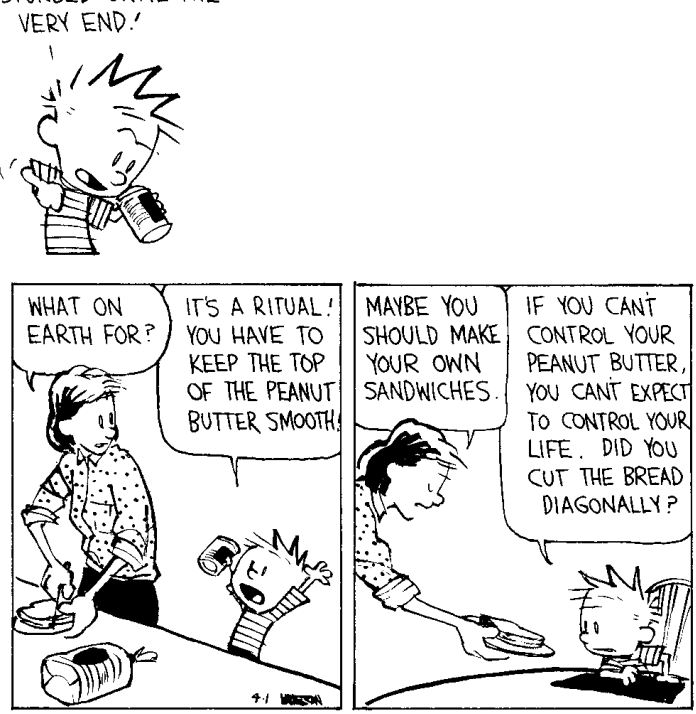

CALVIN AND HOBBES $\odot 1993$ Watterson. Reprinted with permission of UNIVERSAL PRESS SYNDICATE. All rights reserved.

Calvin, who introduces this collection of essays on ritual in its own right, understands ritual as well as many anthropologists. Calvin is dramatizing thematics that I am trying to avoid. Complaining about the peanut butter, spoiled because his mother did not observe the proper ritual for scooping it out, he is telling us: do the ritual correctly. It exists because it has a function-control. Perform control in your ritual, and you will have control in your life. The ritual of how to scoop out peanut butter is a representation of life. Living produces its own symbols, its own reflections, and these are the ritual, existing to 
enact themes of living-here that of control. The ritual has meaning, otherwise why the argument between Calvin and his mother over its importance for living? For Calvin, scooping out peanut butter is akin to a Geertzian model of and model for living-you scoop peanut butter the way you live your life. One thing is certain: to understand the peanut butter ritual, one begins with life, not with a jar of peanut butter. First, though, let's have a look at the peanut butter in the jar ...

Some three decades ago, Claude Lévi-Strauss called for the study of ritual "in itself and for itself ... in order to determine its specific characteristics" (1981, 669). Lévi-Strauss's concern was to distinguish ritual from myth, his overriding focus of study. He identified myth with mind and thinking, and ritual with living and the attempt to overcome any break or interruption in the continuity of lived experience, the discontinuous made continuous (674-675). Ritual, he wrote, "turns back towards reality" (680) in that "[i]t is not a direct response to the world, or even to experience of the world; it is a response to the way man thinks of the world" (681). Lévi-Strauss worried that ritual commonly is conflated with myth-in other words, that ritual too becomes a repository of beliefs and representations connected to cultural philosophies about the world. In a more Turnerian, Geertzian, or, for that matter, Leachian idiom, ritual is perceived and made into a storehouse of symbols and scripts originating in the world outside ritual, activated within ritual in prescribed ways on predicated occasions, in order to inform and to somaticize participants with appropriate meanings and feelings related directly to their cultural worlds outside ritual. In Geertz's terms, borrowed from the philosopher, Max Black, ritual acts as a model of and model for cultural worlds, yet never ritual in itself and for itself, but always ritual as representation-the hegemonic modality for the study of rite in anthropology. A second, powerful modality, whose logic parallels the first, is ritual understood as functional of and functional for social order, a line of inquiry whose interior logic is no different from that of ritual as representation. A third modality, close to the first two in its logic, is ritual understood as yet another arena for the playing out of social, economic, and political competition and conflict.

The way of thinking on ritual outlined in this introduction is not that of LéviStrauss, nor does it pursue his quest for universals, yet it originates from a not entirely dissimilar premise: if one wants to think about what ritual is in relation to itself, how it is put together and organized within itself, then first and foremost ritual should be studied in its own right and not be presumed immediately to be constituted through representations of the sociocultural surround that give it life. William of Occam's Razor is apposite here. If one is interested in ritual as phenomenon-in itself, for itself-then be parsimonious, first exhausting what can be learned of ritual from ritual and only then turning to the connectivities between ritual and wider sociocultural orders. Attend first to what seems to exist within a particular ritual by, as Gregory Bateson $(1977,239)$ put it, declining to pay attention to other suppositions as to how the ritual is constituted. Nevertheless, as I indicate further on, this is not a hard and fast distinction but one predicated on degrees of momentary autonomy of ritual from social order. 
Here, the Razor carves parsimoniously in the direction opposite to that which is near-canonical in anthropology-there, ritual is a treasure house of culture and society, epiphenomenally shaped to reflect and to reflect on the latter. Though this may be so for particular rituals, it is a matter not of a priori theorizing but rather of the analysis of particular ritual forms (Gerholm 1988; Smith 1982). Put otherwise, what particular rituals are about, what they are organized to do, how they accomplish what they do, are all empirical questions whose prime locus of inquiry is initially within the rituals themselves. The Razor slices open vectors of studying ritual within itself and its doing, within its interior dynamics and practices, and not initially from within the wider sociocultural fields within which ritual is embedded. To begin the analysis of ritual as phenomenon in its own right, no assumptions need be made immediately about how sociocultural order and ritual are related, neither about the meaning of signs and symbols that appear within a ritual, nor about the functional relationships between a ritual and social order. It is the phenomenal of the ritual itself that is the problematic at issue-a question perhaps even more of the logos of the phenomenon than of the phenomenal. And, more broadly, this problematic may be phrased as that of the extent, if any, to which particular phenomena have degrees of autonomy from the worlds that create them; whether such qualities of autonomy are significant; and, if so, what such significance might be about. The sole way in which to address this problematic is to make ritual phenomena themselves the locus and focus of inquiry.

None of the above claims that ritual phenomena exist independently of cultural and social orders. But the issue is how phenomena do exist as such in the social world. Phenomena are thus only if perceived to exist. Phenomena exist because they are perceived to be imbued with the real. This immediately implies that phenomena have degrees of autonomous existence-in other words, though always to varying degrees and through various qualities, they do exist in and of themselves. Nonetheless, these degrees and qualities of autonomy are profound, for they seem to relate to what may be called the interior complexity of how phenomena are organized. In turn, the interior complexities of phenomena likely are related to what persons can do within them, and how they act on persons.

This discussion continues earlier arguments intended to forgo claims to the value of any universal, overarching definition or conception of ritual (Handelman 1998, n.d.a). ${ }^{1}$ No theory based on representation or functionalism can open to the tremendous diversity of phenomena that are called 'ritual,' and to their kinds and degrees of interior complexity. Yet my argument does not support a simple cultural relativism of ritual phenomena, aiming instead for a more comparativist perspective towards the integrity of ritual phenomena as phenomenal. Nevertheless, this orientation also shifts from a logos of the phenomenal towards one of the phenomenon.

In general terms, I suggest thinking about ritual in its own right through two steps. ${ }^{2}$ The first is to separate (to an extent, arbitrarily) the phenomenon from 
its sociocultural surround, from its 'environment,' in order to analyze it in and of itself. This analysis is not an end in itself, but is intended to be taken heuristically as far as one can. The second step is to reinsert the ritual into its surround, with the added knowledge of what has been learned about the ritual, taken in and of itself. The first step is more phenomenological, the phenomenon existing in its own right, together with the attempt (necessarily impossible) to exhaust the significance of its forming. The second step is more hermeneutical, including meaning that extends towards the phenomenon from its surround. These steps illuminate whether-and if so, how-the ritual can be said to have its own interior integrity, and therefore whether it exists more as a representation of sociocultural order or more through its own autonomy from such order. In turn, this may clarify how the ritual as phenomenon relates to sociocultural order, without necessarily slipping into an inherently functionalist understanding. ${ }^{3}$

This perspective was put to the contributors of this volume in the following way: "We propose the following thought experiment, in order to try to learn whether ritual forms may have constituting (and self-constituting) features-structural, processual, transformational-that may inform us as to how these rituals are organized in their own right. The thought experiment asks that each of us think about a particular ritual form or forms apart from their cultural and social contexts, in order to gauge whether there are constitutive features of ritual (of its organization, its practice, its cosmo-logic) that can be identified, without comprehending these features immediately as representations of broader cultural and social orders. We call this a thought experiment because it does requires the suspension of disbelief-the anthropological disbelief that aspects of ritual may be understood with value, apart from their cultural and contextual positionings. The results of our work probably will be disparate. Yet, these results will aid in trying (once more) to evaluate whether ritual must be understood as representation, or whether (even for the sake of argument) by suppressing representation we can glean insights into the domain of ritual in its own right."

We did not insist that the contributors accept this perspective. On the contrary, we preferred to let each scholar find his or her own way in accepting, rejecting, or modifying the problematic of ritual in its own right. Phrasing the problematic as 'ritual in its own right' keyed the contributors into deciding whether to foreground or to background ritual in their discussions. Though this makes for a diverse set of essays, it does engage a more honest grappling with the problematic, one that we respect fully. The results are creative, eclectic, fruitful, and sophisticated, raising a range and depth of issues deserving consideration and discussion. Before going on to explore one avenue of thought regarding ritual in its own right-how ritual may be thought of as self-organizing, and so with degrees of autonomy from its sociocultural surround-I introduce briefly the contributions to this volume. 


\section{The Studies}

The two essays in the opening section, "Theorizing Ritual," incisively critique twin canons of ritual studies in anthropology-that ritual is constituted as representations of the broader order of things, and so that ritual must engage with meaning in its doing, often with its own meanings for that very order. Bruce Kapferer's contribution shifts analytical focus from representation to process. Kapferer notes that representation is closely allied with function, and both, I add, are lacking in agency. Since ritual hardly exists apart from its practice, this lack of agency is especially ironic. Moreover, Kapferer comments that anthropological studies of ritual are largely formulated through conceptual perspectives that themselves are not grounded in the close study of ritual-precluding the possibility of learning from ritual in its own right. Through discussions of Victor Turner, perhaps the pioneer of processual analysis through ritual, and Suzanne Langer, Kapferer argues that the interior dynamics of ritual are oriented towards creating, generating, and producing effects. Some rituals gain their potency by being independent to a degree of larger realities and are therefore independent of representation. This insight leads Kapferer to conceive of ritual as a virtuality (in Gilles Deleuze's terms), with the interior dynamics of ritual actively transforming existentialities through the potentiation of its potentialities. The very nonreferentiality of virtuality to the world outside itself enables entering into life's vital processes within ritual, in order to adjust their relationships to the larger world.

Don Seeman's essay takes issue with the position common to Max Weber and Clifford Geertz that ritual is the response-indeed, the meaningful answerto theodicy. As such, theodicy exhausts the significance of ritual, making its existence dependent (functionally) on infusing suffering with meaning. Ritual represents suffering in meaningful ways, thereby making it explainable, bearable, justifiable. Ritual in its own right immediately questions the taken-forgranted coupling of ritual and theodicy. Seeman argues that suffering exceeds culture, exceeds meaning. In the Weberian interpretive paradigm of verstehen, meaning is the rational response to indeterminacy and uncertainty, shaping these within parameters of the manageable-socially, personally. Theodicy thereby justifies itself through ritual, as then does culture, since ritual is formulated as the representation of culture.

In terms of ritual in its own right, Seeman, marking the uselessness of suffering, rejects the Weberian paradigm of the ever-presence of meaning. The suffering of pain, he writes, invokes alterity, making space for the other denied by the self-consciousness of attributing meaning through representation. The person experiencing pain becomes an irreducible other to himself within himself, one hardly given to representation, and so impossible to ignore. In these terms, Seeman addresses changes in the emotional cosmology of R. Kalonymos Shapira in the Warsaw Ghetto of World War II. Experiencing radical, unbearable suffering, Shapira breaks with theodicy. Through this excess of pain he comes to suffer for the other, for God, thereby rescuing agency from the ruins of meaning. 
Man comforts God through ritual. Seeman draws Shapira into Emmanuel Levinas's exegesis on the refusal of meaning embedded in the ethical turning to the other, distant indeed from the self-absorption of interpretive anthropology. Only the refusal of meaning enables man to succor God, an ethical act itself beyond meaning, fraught with the dynamics of cosmogenesis.

The second section, “Experimenting with Ritual," addresses experimentation through ritual. Since all rituals are constructed, at one time or another they were all experimental forms in human design-virtualizing, modeling, refracting, representing. Ritual in its own right encourages thinking more directly on the relationship between design and outcome. Michael Houseman (together with Carlo Severi) has developed a 'relational' approach to understanding ritual. The practice of ritual enacts relationships. No less, ritual reorganizes disparate elements into interdependence within the new totality of a ritual performance. Thus, ritual makes relationships.

To experiment with the making of the relational, Houseman invented an initiation rite and practiced it together with students in his seminar. He was concerned to design a ritual that generates difference (in this case, gender differences grounded in new knowledge through initiation), while making these differences deeper and more concealed than they appear on the social surface, thereby ensuring their naturalization, to be taken as unalterable. Houseman understands the making and naturalizing of difference as the primary goals of initiation rites.

Houseman begins with what I refer to as the first step-inventing the ritual separated from its context. The rite (The Red and the Black) did not grow from context, representing social order, but was used by Houseman to operate on social order-in fact, to recontextualize this. Houseman shows how the outcomes of the ritual honed gender differences beyond the rite itself. In effect, this was the second step-reinserting the rite into social order. Houseman demonstrates just how crucial phenomenal form and its dynamics are in embodying and shaping difference. Even with made-up, utterly meaningless 'cultural contents' that deliberately represented nothing, the rite itself had powerful effects. If one begins with the cultural contents of ritual, the event immediately is made to represent these contents, and the possibility of learning from ritual recedes from view.

André Iteanu rejects the claims of ritual in its own right. Nonetheless, I think he identifies the premises of ritual among the Orokaiva peoples of Papua New Guinea primarily because he asks whether among them ritual exists in its own right. He finds that in the Dumontian sense, ritual is encompassed by exchange. However, Iteanu critiques Marcel Mauss and Marshall Sahlins for obviating ritual in their analyses of South Pacific social ordersthey conceptualize these social orders as constituted through continuous, horizontal relationships of exchange as a Maussian "total social fact.” Iteanu argues instead that this Maussian continuousness between exchange and ritual passes through a "partial discontinuity," one that transforms horizontal equivalency in relationships among persons into vertical relationships between 
spirits and humans. Thus, the level of spirits is enabled to transmit value to the level of humans. Yet the movement of value is efficacious only if the ritual closes with gifts from the giver of the rite to the participants. These generate ongoing exchange through time in the broader social world beyond the ritual. Iteanu brings ritual back into the debate on South Pacific exchange while qualifying its cosmic role.

Through the discussion of ritual and exchange, Iteanu's contribution raises the problematic of experimenting with ritual. But this time it is Orokaiva who are theorizing their experimentation with new ritual forms in changing social conditions, asking whether these forms are efficacious, and if not, why not. The way these Orokaiva speak of attempts at ritual design has much in common with Houseman's discussion of the way he designed his initiation rite.

The following section, "Ritual and Emergence," relates to changing ritual, on a macroscale, through time, and on a microscale, within and through itself. The latter in particular receives no attention in anthropology and cognate disciplines. The physicist Murray Gell-Mann (in Horgan 1998) once summarized emergence as "We don't need something else in order to get something else." Especially on the social scale of the micro, this immediately concentrates attention on development that emerges from within and through its own interior dynamics. At issue is how ritual changes-being altered and altering itself. In the analysis of ritual as representation-symbolic of, symbolic for-self-altering does not and cannot exist. Change in ritual must be imported. Change will not come into existence through the very practice that makes it present. This position vitiates the whole idea of ritual in its own right, obviating the phenomenality of the phenomenon.

Keying into historical materials through the notion of ritual in its own right, the medievalist Piroska Nagy begins to uncover and shape what she calls "intimate ritual," ritual existing entirely within the individual, opening into inner space/time, perhaps with its own socialities (Handelman 2002). The idea of intimate ritual likely is anathema to scholars of ritual as representation, who would relegate this kind of thinking to the study of psychopathologies. The intimate ritual discussed by Nagy is the European High Middle Ages phenomenon of religious weeping.

Discussions of rituals as historically grounded phenomena are commonplace today. Yet despite the diversity of explanations for the coming into being of rituals, to a high degree these explanations share the following. Historians (and anthropologists) treat pasts as cultures and social structures within which rituals take shape, their forms explained in relation to these grounds. The cultures of the past are foregrounded, their rituals backgrounded (indeed, regardless of duration [see Asad 1993] or scale [for example, Darnton 1985]). In explicating the emergence of religious weeping as intimate ritual, Nagy discusses the cosmological and historical grounds of this development. Culturally, the invisible world was more real than the visible, the latter being a pale reflection of the former. Historically, during that duration the Western church unified and grew, became institutionalized, and systematized theology. Cosmologically, 
intimate ritual was one of the possibilities of the virtual, in Kapferer's terms. Historically and socially, intimate ritual could emerge as a form of resistance to the growing social control of the church.

The intimate ritual of weeping was an individual process that was separated from social order and not socially formalized. Its efficacy of washing away sins, a divine operation on the soul, was hidden. Nagy takes pains to point out that this self-relating to the inner landscape of the human being (Gurevich 1995, 7) was not the discovery of the individual as an independent unit of social existence. Nonetheless, the emergence of this self-interiority led elsewhere. Weeping indexed God's presence within the individual, through which the person remade herself interiorly, presenting the results to others. Communing with God, these persons circumvented church and community. Purifying the soul, Nagy argues, was a process without surcease, a profound interior transformation that continued throughout the life-course of the individual, a transformation that perhaps also overcame suffering beyond meaning, of which Seeman writes. Perhaps Nagy's taking seriously the premise of ritual in its own right has resulted in this reconceptualization of weeping as a religious phenomenon.

André Droogers documents emergence within rituals of initiation among the Wagenia peoples of the Congo. In the Wagenia instance, ritual in its own right highlights the emergence of play and the playful (Sutton-Smith 1997) as a form of alternative reality within ritual. Droogers argues that this reality begins to "lead its own life," and that in being practiced, ritual generates its own emergent phenomena. Through ritual in its own right, its capacities to generate alterations within itself come to the fore. In the Wagenia case, the emergence of ludic behavior in the practice of rite had the effect of positive feedback, the generating of further spontaneous changes. These alterations were synergistic, of ritual evolving during its very practice (Handelman 1999). As ritual evolved through itself, both its interior organization and its relationships to its surround became more complex. To discuss this processuality, Droogers turns to theories of cognition, to connectionism, and to the simultaneities of the parallel processing of cognitive alternatives.

The penultimate section, "Healing in Its Own Right," offers two case studies of healing through contacts with other realities, other worlds. Following on Droogers's use of theories of cognition, the contrast between these two case studies is instructive. In the first, by Galina Lindquist, active participation by the patient is essential to the dynamics of healing. In the second, by Sidney Greenfield, the dynamics of healing almost eliminate the active participation of the patient. Their materials push each scholar in radically different directions in searching for solutions to ritual in its own right.

Lindquist enters the neo-shamanic theory of soul loss and soul retrieval in.order to understand its practice in treatment. Using Vyner's terminology, Lindquist sees these treatments as "rituals of the mind" that unfold primarily within practitioners, a viewpoint that resonates to a degree with Nagy's concept of intimate ritual, though in the latter instance the ritual was embodied almost entirely within the practitioner. Soul retrieval arises from a cosmology in which 
the self of the individual splits during severe trauma. The self-now incomplete, damaged, and lacking an integral part of itself-continues into its future, while the split-off part takes refuge elsewhere, timelessly remaining at the age at which it tore away. During the ritual of retrieval, the shaman searches for the lost part, trying to persuade it to rejoin the self of the patient. The shaman tells the patient of his journey in search of the lost part, shaping a new topology, a virtuality, for the patient to enter with newly acquired memories of her trauma and plight. Within this topology, which Lindquist refers to, referencing Csordas, as that of "imaginal performance" (again resonating to a degree with Kapferer's use of virtuality), the patient journeys to her lost soul part to ask for forgiveness and to accept the conditions that the lost part sets for its return. The narrative, composed together by healer and patient, is crucial to contextualizing the entirety of the latter's dis-ease and healing: without the shared interpretation of symbol and narrative, the rite of soul retrieval cannot exist. Yet it is questionable whether this is a ritual of representation in any straightforward sense. At issue is indeed the transformation of the patient through the rite in its own right.

Lindquist writes that the journeys and narratives nest within one another. Especially striking to me is the way that this ritual is practiced into presence by curves - the journeys, the narratives-curving into themselves, self-closing and enclosing, organizing the temporary existence of the rite. Curvature and its relationship to self-organizing properties of ritual are discussed shortly.

In contrast to Lindquist, Sidney Greenfield addresses a cosmos and healing ritual in Brazil in which the social and cognitive involvement of the patient appears minimal. The character of the Kardecist-Spiritist rite of disobsession leads Greenfield directly to issues of ritual in its own rite. In the ritual of disobsession there is an absence of articulation with any overtly shared cultural premises between healers and patients. The Kardecist cosmos is explained to the patient, albeit minimally, yet the etiology, diagnosis, and treatment are explained to her only after the work of contacting spirits and negotiating with them is done. Geenfield's bold solution to these puzzles is to turn to the biosocial in order to hypothesize how this ritual might affect patients. In his armature are psychosocial genomics in relation to altered states of consciousness (ASC) and the Basic Rest-Activity Cycle (BRAC) of 90-120 minutes duration. The cycle contains the rhythm of dreaming, which continues no less throughout the waking hours of the individual. During the dreaming segment of this cycle, persons are more open to outside influences, to suggestion and light trance states that are used by Kardecist healing, and that, argues Greenfield, may activate bodily systems at the cellular level. Greenfield uses universal properties of human biology and physiology that he argues are embedded in the organization of Kardecist ritual in order to suggest how this rite acts on the patient. Not finding any help in interpretive paradigms of meaning, he moves outside ritual into the interior of human being in order to explain the interior of the Kardecist phenomenon.

The last section of the volume invites a distinguished philosopher-semiotician, Robert Innis, to reflect on issues of ritual in its own right. Innis critiques 
the late Roy Rappaport's major work, Ritual and Religion in the Making of Humanity, through a perspective deriving from Michael Polanyi's theory of tacit knowing. At issue is the crucial question of how ritual is actually assimilated and embodied in practices, of how to join the interior organization of ritual (and its shaping of meaning) to its embodiment within ritual participants-the 'indwelling' of ritual in Polanyi's sense. Innis argues that ritual has the structure of a work of art, of a symbolic artifact (see also Innis 2001). We give ourselves to the organization of symbols as the focus of the felt unity of the self. Thus, existentially, we are embodied within the organization of symbols that becomes self-giving (a perspective that resonates powerfully with Galina Lindquist's study of soul retrieval). This enables Innis to open towards the idea of socially 'thin' or individual ritual that is no less relevant to the cachet of ritual phenomena than the socially 'thick' varieties with which anthropologists usually deal. Therefore, anthropological ideas of ritual, argues Innis, should include ideas of self-meaning, of self-giving integration (remarkably paralleling Nagy's discussion of religious weeping in this volume in relation to the presence of God within the person, and likely relating to Levinas's ethics of alterity, examined by Seeman).

In further discussing the studies in this collection, the epilogue addresses the question of just how social ritual should be in order to be thought of as ritual, then moves beyond this into issues of the phantasmagoric and the imaginary.

\section{Towards Ritual as Self-organization}

It is self-evident that the phenomenal world is constituted by phenomena that are culturally perceived, if not socially constructed. It is less a truism to say that social phenomena are made to have, or to acquire, different kinds and degrees of complexity within themselves and in relation to their surrounds or environments. Emphasizing the existential 'withinness' of phenomena points to their irreducibility to the intentions and desires of their makers or shapers. It is essential to underscore here that though phenomena are of course breakable, they are never reducible without doing violence to their self-constitution. Fragmenting phenomena leave traces of their self-constitution, but their reduction erases even these. Social phenomena exist as phenomena, and so they exist in their own right, however fragile and transient this existence may be. Social phenomena, then, have self-integrity, with its intimations of integration. But selfintegrity, the interior capacity of phenomena to sustain themselves, varies in kind and degree.

What we are calling 'ritual,' however loosely, is treated here as a class of phenomena whose forms, in greatly differing kind and degree, are characterized by interior complexity, self-integrity, and irreducibility to agent and environment. Thinking of ritual in this way is attempting to recover aspects of its phenomenality, yet doing so in the domain of the micro, the domain in which ritual phenomena are practiced. This is important because the ideas I am using here 
parallel to some extent macrodomain discourses-called, variously, autopoiesis, synergetics (Haken 1993; Knyazeva 2003), complexity theory (Turner 1997), self-organization, and so forth-coming from the physical and biological sciences but resonating or made to resonate, if somewhat crudely, with 'social systems.' The distinction here between ritual as a microdomain of organization and the macrodomains of social systems is crucial, because the claims I make for the organization of microlevel phenomena differ markedly from the requirements needed to think about macrodomain systemics. ${ }^{4}$

Perhaps the most elementary premise informing all approaches to self-organization is that this is possible only when whatever is being organized is self-referential or self-reflexive (Baecker 2001) -in other words, when whatever is organizing begins to put itself into its own organizing, so that whatever is organized until then influences whatever continues to be organized. Autopoiesis, for example (the term, coined by the biologist Humberto Maturana, literally means 'self-making'), refers to dynamics through which "realities" come into existence "only through interactive processes determined solely by the organism's own organization” (Hayles 1999, 138). In my terms, the phenomenon organizes (in varying degrees) the phenomenon. If autopoietic relationships become fully systemic, the system self-reproduces: "[I]t produces the components that produce it” (Bailey 1997, 86). In terms of ritual, one may argue-again, always in degrees - that a ritual produces the persons that will produce the ritual as that ritual that produces them (see Hayles 1999, 139). Thus, social autopoiesis or self-organization generates degrees of autonomy of the social phenomenon from its social surround (Mingers 2002, 294). As such, the integrity of the phenomenon-the practices that hold it together-derives in degrees from within itself and less from its social surround. In relation to social phenomena, I emphasize the subjunctive character of this condition. Nonetheless, some social phenomena, some rituals, likely approach this tightly knit condition of becoming. In this volume, perhaps the tightest fit between self-production and the transformed self is in Nagy's conception of intimate ritual with regard to medieval religious weepers, but also in Shapira's self-other transformations. Kapferer's (1997) analysis of the Sinhalese Suniyama exorcism as a virtuality is an instance of a high degree of self-integrity and self-organization in ritual.

Self-reference entails making distinctions (Kauffman 1987, 53), in the simplest yet crucial instance for our discussion, a distinction that the self-referential phenomenon makes between itself, in the very practice of self-referencing, and what I am calling its environment or social surround. Houseman designed his ritual, The Red and the Black, so that it had to practice making gender distinctions, while these distinctions then had to be incorporated within the ritual as it proceeded to make gender distinctions. This is in keeping with Niklas Luhmann's (1997) argument that self-referential distinctions, such as those the phenomenon makes between itself and its social surround, are reintroduced within the phenomenon itself, as integral to its self-organizing properties (see also King and Thornhill 2003). ${ }^{5}$ Then the social phenomenon may be said to 'look' inward in order to 'look' outward, and to re-enter its surround from 
within itself. In another terminology, the social phenomenon includes the other or otherness within itself-both differentiating itself from and relating to this. Again this is a matter of degree, shifting between the possibilities of the other as representation and the other as the emerging grounds for the transformation of being within ritual. This is what enables some rituals (which I will call more complex in their organization) to act on their social surround: in the very practice of separating itself from its social surround, the ritual contains the surround, thereby acting on the surround through what is done within the ritual. This may be what enables man to feel ritual compassion for God in Seeman's discussion of Shapira, and no less enabled Nagy's medieval weeper to be transformed by God's compassion. Kapferer's conception of virtuality, for example, through the creation of cosmos from within itself, speaks directly to these issues (Kapferer 1997).

I suggest, then, that within ritual forms, autopoietic qualities of self-organization and qualities of complexity go hand in hand. Perhaps the greater the degree of interior complexity within a ritual, the greater will be its tendency to self-organization. And so, the greater the tendency to self-organization, the greater the capacity of the ritual for temporary autonomy from its sociocultural surround. Then, one step further, the greater this relative autonomy, the greater the capacity of the ritual to interiorize the distinction between itself and its surround and so to act on the latter from within itself, through the dynamics of the ritual design. Of the rituals discussed in this volume, all, perhaps with the partial exception of the Orokaiva instance, are or were intended through the practice of their forms to change one or more of their participants.

Topology (in a loose, nonmathematical sense) is relevant here because of its concern with form as self-connectivity (McNeil 2004). The topological movement from lesser to greater self-organization can be likened to that from a straight line to that of a curve, though in social terms it may be more advantageous to speak entirely of degrees of curvature. The less the tendency of a ritual to self-organization, the more its interior operation is akin to a straight line, a 'line,' moreover, that continues from and is continuous with its sociocultural surround, its existence dependent on representing the latter. Such ritual derives directly from its surround, hence its linear relationship to the latter and, too, the lesser complexity of its interior organization. ${ }^{6}$ Here map is close to, almost isomorphic with, territory. By contrast, the more the tendency of a ritual to selforganization, the more its interior organization is akin to a curve, one that arcs away from the immediate embrace of its sociocultural surround and moves towards self-enclosure and increasing self-integrity.

The self-referential existence of cultural forms, their degree of self-organization and self-integrity, is intimately related to issues of recursion. Bateson gives a simple physical example of recursion: a smoke ring, a torus, turning in upon itself, giving itself a separable existence. "It is, after all," writes Bateson (1977, 246), "made up of nothing but air marked with a little smoke. It is of the same substance with its 'environment.' But it has duration and location and a certain degree of separation by virtue of its own in-turned motion." This torus is an in-curving 
form containing the beginning of elementary self-reference, the hallmark of integrity, and so of self-organization, itself existing through recursion (on the movements of the mathematical conception of torus, see McNeil 2004, 19-25).

The social torus is constituted through a double movement: curving inwards, torquing outwards, through form recognizing itself within itself, and on the basis of this self-integrity moving outwards, driving into broader cosmic and social worlds. ${ }^{7}$ This double movement, inwards and outwards, is crucial to the existence of any social form containing within itself the potential for self-organization, the propensity for the forming of difference within itself and for exfoliating this, twisting it back into the broader sociocultural surround. ${ }^{8}$ The double movement-simultaneously curving towards closure and twisting towards openness-baldly describes ritual in its own right, separable yet inseparable from its surround. As separable, ritual can be examined as such. As inseparable, ritual twists back into relations with the broader worlds within which it is embedded and from which it takes form. ${ }^{9}$

Through their self-curvature, social forms, enclosing themselves within themselves as vectors of action, give themselves intentionality, organization, depth, and direction-in other words, shape. ${ }^{10}$ Recursivity in a sense gives itself a push, a "phusis" (Castoriades 1997, 331), towards completing what has been set in movement-these are the pulling qualities of propensity embedded in self-organization. No social form has the autonomous existence of absolute difference, yet without minimal self-propelling difference, no social form exists as it does, for whatever duration, under whatever conditions. This propensity to self-organization is present in the most mundane of everyday behavior and interaction. Studying face-to-face interaction, I was struck by how, whenever two or more persons began to interact, the double movement of curving towards closure and twisting towards openness came into existence, taking phenomenal shape. I coined the adage that in social interaction between two persons, one plus one never equaled two. Persons interacting were never the sum of their parts, since their interacting was mediated by the emergence of ephemeral, organizing forms whose duration was that of the interaction itself and whose emergent structures influenced the character of interaction as it emerged. Reshaping Erving Goffman's (1961) concept, I called these transient, yet continually present, emergent forms "encounters" (Handelman 1973, 1977)."

Important again is the double movement-of an everyday encounter emerging into phenomenal form, curving towards self-closure, to some degree of self-organization, however momentary, however transient, separating itself temporarily from the social field, existing in its own right, then ending, twisting back, torquing into broader social fields, dissipating, its character influencing encounters to come. Interpersonal encounters have self-organizing propensities. In mundane life these properties are often emergent phenomena of interaction as it is occurring. Though these properties differ vastly in their degrees of complexity, they curve recursively as they emerge, shaping the ongoing interaction. Self-organizing phenomenal forms have variable capacities to generate new aspects of themselves, during their operating. Even in highly rule-governed 
contexts, social interaction contains the potential to generate creativity, which may (or may not) become part of the curve towards phenomenal self-closure. ${ }^{12}$ Social form is always in movement within itself. Luhmann $(1999,19)$ writes that "form is the simultaneity of sequentiality," the compression of its dynamics. Form exists through its dynamics of self-forming and dissipation.

Forming form-phenomenal form emerging through practice-does not necessitate any principled distinction between mundane living and ritual (Handelman 1979). Both domains exist through the forming through practice of temporary, interactive social units-of whatever duration, space, and significance-that rejoin the sociocultural fields from which they emerge. The signal difference between mundane encounters and ritual may be more in how they self-organize and less in any meta-definition of sameness and difference from which all else follows-a position that still dominates attempts in anthropology to define ritual.

The phrasing of this introduction addresses ritual as a curving towards selfclosure and self-organization, and as whatever depth and innerness this enclosing opens. Witness the insistence of so many rituals that they go elsewhere, elsewhen, within and through themselves. The movement from the line to the curve is that of conditions of self-organization. Curving, the line becomes selfreferential, opening space, acquiring depth. In relating to itself, the curve organizes itself in terms of itself, thereby enabling its existential and phenomenal self-organization as different from whatever exists outside the curve, while including this distinction within its self-referentiality. As Bateson $(1977,242)$ implies, phenomenal forms "survive through time only if they are recursive. They 'survive'-i.e., literally live upon themselves-and some survive longer than others." In these terms, sociocultural phenomena differ in the resources they have to live on, within themselves. When self-organization becomes highly complex, a ritual has more to live on, or rather, to live through, and we may speak, rightly so, of a separate world of causation and action, one in which, perhaps, all tenses exist simultaneously within self-same space. ${ }^{13}$

These thoughts on phenomena as inwardly curving self-enclosures resonate with Deleuze's interpretation of Leibniz's 'fold.' The fold may be conceptualized as the forming of a pocket of social action, as a folding in of movements of living, articulating persons within these curving self-enclosures in certain ways, not in others. As it curves, the fold or pocket opens the depths of space/time where/when no opening had existed a moment before. The opening itself is a curving of space/time, since the movement of living is neither stopped nor blocked, but shifted into itself, enfolded, reorganized, and thereby made different, minimally, partially, utterly, from the movements of whose courses the opening is but a moment. The fold or pocket inflects and involutes (Deleuze 1993, 14-26), entailing variable and varying degrees of self-organization, the autopoietic propensity that follows from the self-closing that is the curve. Yet the pocket is partial because the fold twists back, torquing into the movements of living, refolding again in similar and dissimilar ways. The fold curves recursively because its forming is anti-Cartesian, turning over and 
upending the monothetic, and so resonating with many of the traditional and tribal rituals for which we have substantive ethnographic evidence-but no less with medieval religious weeping as intimate ritual, with neo-shamanic soul retrieval, with the experimental (The Red and the Black), with Orokaiva ritual discontinuity, and perhaps, too, with human being embracing some part of God in her compassionate embrace.

This is no small matter, since numerous indigenous claims and exegeses insist that ritual does something-often transformative, temporarily, permanently-to cosmos, to participants. The doing of transformation through ritual requires curvature, the opening of space/time within which cause and effect can be joined self-referentially, such that each embeds knowledge of its relation to the other, thereby together influencing one another recursively in predictive, controlled ways. Cause and effect find one another through self-referentiality. To do controlled transformation, a ritual form must 'know' it is doing this, in order to recognize change as both property and product of its operation. Curvature creates the existential knowledge of what it is that is curving, as distinct from whatever realities the curve emerges from and returns into. Moreover, curvature creates the existential knowledge of how what it is that is curving is changing as it is curving, so that, for example, more interiorly complex ritual is continuously becoming other to its-self as it is practiced, since it necessarily is changing in relation to its-self.

Folding, curvature, recursivity, self-referentiality, all are elemental to the idea that some forms of ritual must be separated from the sociocultural orders that create them, and thereby that these forms temporarily are made autonomous of these surrounds. This was an implicit insight of Van Gennep and Victor Turner on rites de passage as the organization of social and self-transformation. Liminality is a space/time of curvature, of renewal, rebirth, resurgence, reshaping, remaking, and so forth. But liminality also is the folding of space/time into itself, such that whatever enters, wherever, is made to relate to itself differently, coming out elsewhere, otherwise. Nonetheless, as noted, we should never forget that the relationship of lineality $\sim$ curvature always is relative, and so that degrees of curvature, degrees of lineality, are ratios of self-knowledge and self-organization of and within ritual forms.

Claims coming from anthropology often weigh in from extremes: arguing on the one hand that if ritual does something, then either this is done through representations within ritual of the broader sociocultural order, enabling ritual to reflect or radiate how values, ideals, and relationships should be shaped and resolved, symbolically, functionally; or, on the other, that ritual is organized to act directly, causally, on sociocultural order. Both positions are valid, since each is related to the kinds and degrees of self-closure of a given ritual. From this perspective, ritual becomes the self-organizing of kinds and degrees of closure and their consequences. Therefore, variation in parameters of selforganizing should be sought and explored within any given ritual. These parameters also become one guideline for a comparative study of ritual that focuses on ritual form and its doings. 
The above points to the error of thinking that a singular conceptualization or definition of ritual can encompass, let alone index, all 'ritual' phenomena. Though all social phenomena are interactive and so have some degree of curving self-closure, varying from the nearly flat to the near autopoietic, their variations in self-organization relate, as Bateson commented, to the degrees of self-sustainability of sociocultural forms in their surrounds. I relate these variations in self-organization to the capacity of rituals to make difference or change occur through their own operations. Put simply, the more a ritual curves into the foldedness of self-closure, the greater its self-organizing and self-sustaining capacity, and because of this, the greater its capacity to effect difference or change through its operations-thus, the more distinctive its torquing back into social order.

This discussion continues the spirit of the thought experiment suggested to this volume's contributors, of an experimental moment, one asking what, if anything, can be discovered about the operation of ritual in relation to itself, rather than worrying immediately about the truth-value of this exercise. The truth-value of this moment is never complete without the second part of the movement, ritual's twisting back, torquing into sociocultural order. Nonetheless, scholars who insist that canons of scientific validity and its truth-claims are always at the forefront of brainstorming are unlikely to respond with any enthusiasm to this exercise. Ritual in its own right is not an end in itself but rather a perspective, a way of inquiring into ritual forms, into how rituals are put together, into whether, how, and to what degree such in-turning compositions have self-integrity. Rather than, "anything goes," as Feyerabend $(1978,28)$ put it, one can say that what goes around, if it comes around, does so with difference. What comes around, then, is more toroidal than spheroidal.

Beginning with ritual in its own right turns the canonical study of ritual on its head, since it obviates representation - the entire gambit of models of, models for, including the reign of the symbolic as symbolic of, and the functional as functional for-as an inherent (and oft-thought sufficient) condition for the existence of ritual phenomena (see, for example, Bloch 1992; Geertz 1980). This obviation of the necessity of representation includes the idea that ritual should be cultural self-narration (Geertz 1973) or that it must be a working out of social relations (Gluckman 1962). Instead, I am arguing that a radical way through which to learn of the relationship of ritual to social order is to examine first and foremost what, if anything, can be gleaned about a given ritual in relation to itself. The initial intention is to explain ritual more as phenomenon, as form, and less so as social order. Therefore, my premise is one of the a-representativity of ritual phenomena, a position neither pro- nor anti-representation.

The degree to which the interior organization (and therefore dynamics) of particular ritual forms are dependent on their representations of sociocultural order becomes an issue for study. From the perspective of particular ritual forms, it is social order that may be perceived as radically other rather than as continuous with these rites (de Coppet 1990). Or from Kapferer's perspective, the virtual has the potential to generate all possibilities that a ritual is capable 
of actualizing in particular conditions of practice, including its generation of the sociocultural surround. ${ }^{14}$ So, too, the way opens to considering whether a particular ritual form has self-organizing qualities. If a particular ritual form has minimal self-organizing properties, in such instances the definitiveness of the distinction between ritual and not-ritual may turn out to be irrelevant (de Coppet 1992, 2-3), or at least much less definitive, a contention borne out from within ritual by Iteanu's contribution.

\section{Thinking on Ritual in Its Own Right}

To amplify this introduction, I discuss three ethnographic instances, adding practice to my argument for the theoretical value of learning about ritual through ritual. Each instance is discussed in terms of the two dynamics raised earlier: the degree of self-closure in the rite, and its twisting back and torquing into social order. In my reading, the first instance discussed has hardly any selfclosure or tendency towards self-organization, and so has little or no twisting back; the second has self-closure coming into existence, but it is not sustainable, and one cannot quite speak of its twisting back; the third has complex curvature, the highest degree of self-closure and tendency towards self-organization, and undoubtedly twists back, powerfully torquing into social order. These two dynamics correspond to the two methodological steps outlined previously: first, separating the ethnography of the ritual from its social surround in order to discuss it in its own right, and, second, re-embedding the ritual in social order.

\section{Minimal Self-closure: Maria Antonia Crosses the Rhine}

The first instance, from eighteenth-century Europe, is that of Maria Antonia, the fourteen-year-old daughter of Austrian Empress Maria Theresa, on her way to France to wed the Dauphin, the future king, Louis XVI. Stopping at the Rhine, she was turned from an Austrian princess into a French one. This exchange of one identity for another had been preceded by intensive pedagogy at the Austrian court: instruction to perfect her French; lessons in deportment and appearance, suitable to Versailles; changes in hairstyle; learning the latest minuets and fashionable card games; practicing the variety of bows and curtseys required by court etiquette; discussing matters of state and polity, and so on. A series of rituals had been practiced, including the French ambassador's state entry into Vienna, Maria Antonia's renunciation of all her hereditary rights, and her marriage by proxy to the French Dauphin (Haslip 1987, 4-8).

Her exchange of identity took place in a pavilion on an uninhabited island in the Rhine. The pavilion had five rooms, two facing east (towards Austria), two facing west (towards France), and in the middle a large hall where she was to be given over to France. Prior to this, Maria Antonia shed her Austrian garments and was redressed "in the embroidered shifts and petticoats of her 
French trousseau, the silk stockings from Lyons, the diamond-buckled shoes from the court shoemaker of Versailles. Her Austrian attendants, many of whom she had known from childhood, came forward to bid her a last tearful goodbye ... As formally as in a minuet, in which every gesture had been carefully rehearsed, Marie Antoinette was now handed over to her new country. Prince Starhemberg led her up to a raised dais in the central hall, in front of which was a long table representing the symbolic frontier between France and Germany. Here waiting for her were the French envoys with the official documents" (Haslip 1987, 9-10).

In France, Marie Antoinette was married again, and entered into a series of rituals in which she was continually on display, in accordance with the etiquette of Versailles. Architectonically, Versailles embodied the king, and Marin (referring to Louis XIV) describes the topography as a "perfect simulacrum" of his portrait (1991, 180-181). In a sense, then, these rituals were practiced within the encompassing body of the king, the simulacrum fully continuous and perhaps isomorphic with its surround. The rituals of display were continuous with their surround. These rituals included the royal card game, the wedding banquet (held in a new theatre), and the levee-Marie Antoinette's daily rising from bed through acts of dressing in which every piece of clothing proffered her indexed the (changing) status and prestige of the performer. The levee of the king was even more complicated in the number and variety of categories of person who had roles to play in his getting up from and going to bed. These and other royal rituals of etiquette were the stuff of court life, ongoing arenas for competition over status in which the slightest fluctuation in value was registered immediately by the participants (Elias 1983, 78-116).

The interior organization of the fold in mid-Rhine leads not more deeply into itself but immediately outside, towards the courts organizing this formal exchange. There is no double movement of curving interiorly and torquing anteriorly in this rite of exchanging the archduchess for the dauphine. One act leads additively to the next, then to the next, and so on. The curvature of this pocket is nearly flat, its trajectory shallow, barely recursive, forging forward into the next ritual display, and then the one after, and the one after that. The princess is entirely a vehicle of the symbolic, exchanging one set of representations for another. The persona of an Austrian princess is exchanged for that of a French one.

Despite the intricacy of protocol, the demeanor of personae, the multivocal symbolism of dress, and the political maneuvering, the ritual in mid-Rhine has no self-organizing properties. The ritual lacks complexity in relation to itself. In its entirety, this ritual (and all the others of the series, perhaps with the exception of the marriage rite) is lineally continuous with royal social order on each side of the river, and reflects this in its transfer of representations from one authority to another. The significance of this ritual is wholly in its representations, as symbolic of the social orders that gave it shape: a model of courtly form, a model for courtly form. This is clear when the rite is reinserted analytically within social order. 
The ritual in mid-Rhine was isomorphic with the organization of court life outside the rite. The ritual was another piece of the broader social matrix and was not divisible from this. The action within the ritual was entirely a manifestation of the patterning of court life. Here, ritual in its own right tells us that Maria Antonia's change of persona did not exist in its own right. There likely was no experiencing from the world within the rite of the world without as radically different (Foucault 1993, 59)-as I would expect to be the case in rituals with more powerful properties of self-organization. In this instance, the distinction itself between ritual and not-ritual (raised by Iteanu in this volume and by de Coppet and myself elsewhere) may be irrelevant, since both domains were organized according to the same principles of formal demeanor and deference, and to the centrality of public, privileged gaze.

\section{Curving towards Self-closure: The Dancing Regiment}

The second instance provides a sense of how a curvature of social autopoiesis can come into existence, since the instance-one of dance-practices curving self-closure metonymically, through its own movement. The dance is that of a regiment in eighteenth-century Geneva, observed by Jean-Jacques Rousseau. Members of a local regiment, on completing their exercises, ate together as companies. Most then gathered in a nearby square "and started dancing all together, officers and soldiers, around the fountain [in the square], to the basin of which the drummers, the fifers, and the torch bearers had mounted ... the harmony of five or six hundred men in uniform, holding one another by the hand and forming a long ribbon which wound around, serpent-like, in cadence and without confusion, with countless turns and returns, countless sorts of figured evolutions ... the sound of the drums, the glare of the torches ... all of this created a very lively sensation" (Rousseau 1982, 135). It was late, the women had retired. Yet soon the windows filled with female spectators, and then women came out, the wives to their husbands, the servants with wine, the children halfclothed, running between their parents. The dance was suspended and, instead, embraces, laughs, healths, caresses-a mood of "universal gaiety"-prevailed. Rousseau's father, trembling with feeling, embraced him, saying, "Jean-Jacques, love your country. Do you see these good Genevans? They are all friends, they are all brothers; joy and concord reign in their midst." Rousseau commented that he himself still felt this trembling feeling, continuing, "They wanted to pick up the dance again, but it was impossible; they did not know what they were doing any more; all heads were spinning with a drunkenness sweeter than that of wine ... [later] they had to part, each withdrawing peaceably with his family" (135-136).

Ritual in its own right notes that in this instance the opening of space/time immediately curves, the serpentine line of dancers, officers and men together, holding hands, stepping in unison, winding round, through countless turns and returns, to the beat of drums, the puff of fifes. The ritual curves further and further into self-closure, into self-reference, organizing itself over and again 
through its practice. The more the ritual curves, the deeper its self-enfolding. The self-organization of this pocket taking shape through movement is more complex than it appears on its mobile surface. This little world exists through rhythm, and rhythm depends on tempo. Tempo organizes the dancers, enabling them to exist together through rhythm (You 1994, 362). The aesthetic recurrence of rhythmicity and its movement generate their own time/space. Effectively, the dancers and musicians momentarily existed in their own ritual reality, quite autonomous of the immediate surround.

By contrast, the transfer of Maria Antonia according to protocol, from one phase to the next, is more lineally additive than transformative. However, the organizing tempo and rhythm of the regimental dance contain within their forming the propensity to fold. The curvature curves recursively through itself, forming the fold that is the curve enfolding its curvature. Space/time becomes more that of the fold, rather than a representation of the wider world. The winding shaping of this enfolding takes form in relation to the habitat of the square, the positioning of its fountain and that of the musicians. ${ }^{15}$ Without leaving the interior of this rite, we can say that the dancers, though in uniform, likely were in more of an egalitarian relationship to one another than they were in the regiment outside of the dance. The men were doing what McNeill $(1995,2)$ calls "muscular bonding" - "the euphoric fellow feeling that prolonged and rhythmic muscular movement arouses among nearly all participants in such exercises"-though to discuss this further requires more information than the rite in itself supplies.

I underscore that in Rousseau's description of this rite, the double movement of curving self-closure and torquing into exteriority was present to a degree. However, the dance roused unanticipated, emergent action from its social surround. The womenfolk, initially spectators, rushed from their homes to embrace their menfolk. The self-sustaining fold of the dance did not withstand the social surround torquing into the dancers: the uni-form regiment turned into a multitude of family groups, a microcosm of a family-based order, and the harmonics of the euphoric bonding of the fighting men passed into the family groups (witness also the responses of Rousseau and his father). ${ }^{16}$

Given Rousseau's description, this is about as far as one can go in discussing the dancing of the regiment as a ritual in its own right. Here, the movement of social life suddenly (perhaps spontaneously) forms into a powerful self-enclosing curve, a fold self-organizing and augmenting the rhythm and harmonics of muscular bonding. The second step, re-embedding the ritual into the broader surround, implicates other aspects of this event, though without radically altering the rudimentary analysis I have offered of the ritual in relation to itself.

In keeping with this second step, Rousseau wrote that previous to the dance the soldiers had done their exercises and then had supped together in companies. The sequencing is significant, since the dance may have been the emergent property of the men drilling and eating together. By the sixteenth century in Europe, drilling organized soldiers in systems, and the maneuver called the 'countermarch' by the Dutch, turned a body of men with firearms into "a unit of continuous production" (Feld 1975, 424-425), one that folded and self-organized into 
a group that fired continuously-one that, in its own way, danced continuously to the rhythm of serried ranks in movement from front to back, to the tempo of firearms discharging.

The men who danced as a regiment knew the steps, the music, and how to synchronize these, but the dancing at that time and place has the sense of a spontaneous celebration and self-organization of the feelings aroused by drilling and eating together, sustainable for a time through its own propensity to fold recursively (just as drilling instilled). McNeill $(1995,8)$ argues that drilling together produces boundary loss in the individual and a collective feeling of oneness. Eating together undoubtedly enhances such collective feelings, harmonizing people's interiors in concert. Sliding into dance changed the geometries, the topologies of movement of the preceding practices. The dancers joined to one another through the folding, flowing currents of rhythmic movement, synchronization, direction, entering further into the relationship between exterior and interior of individual and collectivity opened by drilling and eating together. The fragmenting of the dance by kin torqued the dancers back into the broader surround, into their families, into another topology through which the military practiced exteriority against the enemy in order to protect the interiority of family units, the core of societal reproduction.

\section{Self-closure and Complexity: Slovene Pig-Sticking (Furez)}

The third instance, pig-sticking on Slovene farmsteads, demonstrates that greater curvature increases the self-organizing complexity of ritual and, furthermore, radically alters what ritual can do, in its own right. I use Robert Minnich's rich ethnography to discuss further ritual in relation to itself and then re-embedding ritual in its sociocultural surround.

The Rite of Pig-Sticking Furez is the day on the Slovene farmstead when pigs are killed and made into sausage and other pork products. The head of the household (gospodar) invites a 'head butcher' and others who will participate in the killing and prepare the meat. Arriving in early morning, the 'guest' butchers assemble around the kitchen table together with the gospodar. The head butcher takes the gospodar's seat at the head of the table, also giving the gospodar's wife, the gospodinja, any special instructions he may have. The mood during the small breakfast is quiet, subdued, solemn, as it is among the women in the kitchen. The head butcher says a prayer, crosses himself, and takes out his dagger-like 'sticking knife,' kept separate from his other blades and used only for killing pigs. The knife is thought to have its own powers and to do the killing, rather than the one who wields it (Minnich 1979, 187, 190).

The head butcher takes the pig out of the sty, and the others pin it down. The women retreat into the house. Uttering, "With God's help," the head butcher thrusts the knife into the pig's jugular vein, stabbing the heart. The head butcher may then etch a cross in blood below the neck (111). Until the pig is dead, there is tense silence among the butchers. Before the butchering 
begins, or before the carcass is taken into the house, it is blessed, sprinkled with holy water at the threshold of the house, or sprinkled with blessed salt by the gospodinja. The body then is convertible for human consumption (114). Usually, both skinning and butchering are done outside, and once these tasks are completed, the body parts are taken inside, where the butchers take over space, though not in the kitchen. Many of the particular cuts of meat and the cured products from the Furez are designated especially for particular meals, ritual and other, throughout the calendar year of the household. These Slovenes say: "Each limb [of the pig] has its own nameday" (107).

With the body parts inside the home, the mood of the participants changes acutely, from withdrawn solemnity to sociability, joking, fun. After a jovial midday meal, the butchers make sausages: raw sausage for smoking, blood sausage, and klobasa, the meat sausage. They shape the first klobasa as a gigantic phallus, or as a double-segment circular sausage with a third segment attached and protruding through the circle, a pointed sign of sexual intercourse (117). Either a butcher brings the phallus into the kitchen or the gospodinja comes to take it. In their separate work areas, the men and women continue their ribald joking about this sausage, which remains unnamed.

As night falls, with the sausage-making and cooking completed, people arrive for the Furez supper. The guests include neighbors, kin, and the wives and children of the butchers. The table is decked in white, the best service is used, and seats of honor are given to the eldest present. The gospodar returns to prominence through his speechmaking. The meal itself is huge and lengthy, with many different sausages, cuts of pork, other dishes, and wine and brandy. Afterwards, the participants dance and sing, even until dawn.

The Rite in Its Own Right These are the bare bones of the event. Most evident is the event's lineal sequencing. If we go by activity and mood, there are three segments. In the first, solemnity and religiosity prevail before and during the killing, and during the skinning and slicing up of the carcass, throughout all of which the head butcher displaces the gospodar. The second consists of bringing the body parts inside the home, with the subsequent sausage-making by the men and cooking by the women. This segment is characterized by fun, ribaldry, sexual joking, degrees of embarrassment, and greater sociability. The third is the festive meal-lengthy, convivial, replete with speeches by the reinstated gospodar and talk, stories, music, and song-embracing many guests.

The segments must take place in the lineal order they do. The pig cannot be killed before the guest butchers arrive and make their preparations. The body parts must not be taken inside the house before being blessed. Joking should not occur before sausage-making begins. The festive meal cannot be held until all of the pork products are ready and additional guests arrive. Each segment corresponds to periods of the day-morning, afternoon, evening. ${ }^{17}$ Each segment has its own high point: in the first, the killing of the pig; in the second, the phalluslike klobasa made of the pig's intestine; in the third, the high conviviality of numerous people, many from outside the farmstead, joining together. The high 
degree of curving self-closure is immediately evident. The pig returns, but different, consecrated, sexualized. The butchers return, but different, their solemnity transformed into jovial ribaldry. The women return; the home returns. The second segment is a recurving of the first, and so forth. Each recursion increases the propensity of folding the rite deeper and more fully into itself, making it more complex, more a ritual existing phenomenally in relation to itself. ${ }^{18}$

In sequence, the three segments also have a sense of climax built into their movement. A high degree of recursion enables transformation. The movement may be glossed as that of death into procreation, procreation into an extended familial order, the fruits of procreation feasting on the death that promises life for the living. The segments are not modular (as those involving Maria Antonia were, to a high degree), in that their order cannot be switched about without utterly altering the integrity of the occasion's recursive folding. On the basis of what we know so far, there is an internal logic to the propensity of the temporal sequencing, one that appears lineal (segment moving to segment) yet is self-closing. The movement of the sequencing is a widening gyre, taking off from the death of the pig and flowing around the farmstead, momentarily changing its interior and its relationship to its exterior. The farmstead is folded into itself, but comes out somewhere else.

This is evident in analyzing movement through space, especially that between the interior and exterior of the farmstead. The household invites outsiders inside. The guest butchers enter farmstead and home, eating breakfast together, the head butcher displacing the gospodar, who, as Minnich comments, becomes a guest in his own home. The border-the distinction between interior and environment, in Luhmann's terms-between the farmstead and its exterior is stretched into the inside, into the home, especially by the head butcher, who is an analogue of the exterior plane of this border. Exterior becomes interior, a fold opening and containing this different order of things as its dynamics. Furthermore, the head butcher, the exterior made interior, moves towards the pig and its destruction. Yet on the basis of ritual in its own right, we cannot say anything directly about the pig and its possible relationship to bordering, since this information is lodged in the sociocultural surround of the ritual.

Nonetheless, we can say that the killing of the pig is marked by bordering signs. With a brief invocation, the killer crosses himself, separating himself from the pig he will kill. His pig-sticking knife has killing power of its own, separating it from the killer who wields it. The skinned corpse is sprinkled with blessed salt, separating it from what it was in life, enabling it to cross the home threshold, from outside to inside. All this suggests that there is something in the pig, perhaps related to its coming death, involving its separation from human beings. Perhaps because pig and human are somehow related, even intimately? When the pig, apparently associated with outside, comes inside, it does so in pieces. An analogue of the exterior, the pig has been taken apart, and it is the interiors of this analogue-especially intestines, stomach, blood-that come inside. Inside, the interiors of the pig are used to alter mood and relationships of the interior of the home. 
The butchers coming back inside the home with the insides of the pig are not the same butchers who went outside to kill that pig. Their demeanor is different, and deep within the home they begin the intimate work of turning the pig's interiors into sustenance. The pig's insides, intestines and stomach, become the container, another recursive pocket within the complex fold, to be filled with the man-made mix of minced pork. Inside the home, the interior of the pig is made into the exterior of the sausage, shaped by the men into signs of sexuality and procreation, cooked by the women and later taken into the interiors of the people who will feast on it. One analogue of exteriority, the butchers, destroys and transforms another, the pig. One sign of the transformed pig, the transformed exterior (sexuality, procreation), is consumed and made interior by the participants, in the course of which they, too, are transformed. The self-organizing properties of Furez operate through this propensity of folding and enfolding the fold that continues to be folded recursively, thereby destroying exteriorities that function in the everyday. Folding within folding generates deep interiority. Thus, this ritual fold generates itself as more autonomous of the everyday, becoming in its own right a specialized context for change that will twist back, torquing into the everyday, effecting this.

Inside the home, both butchers and women are preparing pork as food. This complementarity in work between 'outside' men and 'inside' women is one ground through which they relate to one another. The pig gives its interior to be made into a male sexual organ extruding from the outside male within the home of the inside female. Coming to the women, the penis is cooked, domesticated, perhaps with intimations of fertilization and procreation, perhaps with connotations of the 'birth' of something else, something that will be the 'offspring' of exterior within interior. If so, then this entire process depends upon making the domains of outside and inside, exterior and interior, bend and curve recursively into one another, segment into segment. Beginning with the coming of the guest butchers, the distinction between exterior and interior is enfolded, thereby self-enclosing the fold of the Furez.

What might this birthing be? We know from the ritual that the corpse of the pig is being made into sustenance, and that during its preparation and later as food this corpse is the basis for commensality, sociality, intimacy. We know that later on the festive supper opens the farmstead even further to outsiders, expanding in duration and number. Perhaps this social expansion is the birth of something else?

Everything said so far is accessible through analyzing the ritual in its own right and yet, more significantly, is integral to that ritual, in and of itself-all this without deriving the ritual form and dynamics from the broader order of things, the usual sequence of thinking in anthropological analysis. We see that this ritual has its own integrity of recursive self-organization, and, as such, this ritual form may have the propensity (indeed the interior capacity) to accomplish something that the farmstead cannot do on its own. To discuss this further, I take the second step of re-embedding the ritual within the broader order of things, as its recursion twists back, torquing into the wider society. 
The Rite Re-embedded The Slovene peasant-farmers of this region place great value on the social and economic autonomy of their farmsteads and nuclear families. Autonomy is a bastion of their identity. Farmsteads (not family lines) signify to these peasant-farmers "the continuity and stability of a local social and economic universe" (Minnich 1979, 64). The all-important standing of the gospodar is identified with a place, the farmstead, his "home ground," and not with a family line. On the front stage (though not the backstage) of the farmstead, the gospodar appears as the sovereign of his immediate family. The relationship between gospodars is that of equals, while a gospodar entering the domain of another usually becomes 'guest' in relation to 'host,' accepting the hospitality and authority of the latter.

These peasant-farmers say that Furez is a special occasion practiced annually, preferably close to but before Christmas. The Furez supper is the household's most festive and richest annual meal. The pig is the only animal raised here for slaughter. Its killing is given the special name of pig-sticking, while the infrequent killing of other farm animals is referred to as slaughtering. The pig has an unusual status among these peasant-farmers. More than any other farm animal, the pig is involved in the daily routines of its keepers (134). Swine food commonly is prepared on the kitchen hearth, and there is some sharing of kinds of food among people and swine-cabbage and potatoes, and, in the past, millet and corn. Pigs and farm people, writes Minnich (143), are close associates. Yet unlike other farm animals, pigs are not given names, are not personalized. Moreover, pigs proffer the most prolific referents for local obscenities and sexual joking, while the most powerful rhetorical abuse refers to pigs and their inhuman qualities: "Swine lap up and wallow in their own excrement," and "Sows devour their young" (138). On the one hand, the pig exists only to give its life, but on the other, only for the pig is an annual Furez held.

As a farmstead animal, the pig has a special status-close to people, distanced from people, the nonhuman refracting the human, its death ritualized, its flayed and dismembered corpse intimating sexuality, procreation, commensality. On the human side, the autonomous gospodar abdicates front-stage authority to the head butcher, a 'stranger' to the ideologically independent farmstead. The gospodar thereby distances himself from the killing within his domain. In turn, the head butcher is distanced from the killing by the belief that his special dagger has the power to do the deed and kill. Nothing human, no one belonging to the farmstead, kills the pig. It is not an immaculate death, yet moving in that direction-a death with qualities of an ordeal (witness the change of mood prior to and after the killing) in which the killer takes distance and the corpse is sanctified. Yet what is being killed? And by whom? As I asked earlier, what is being birthed?

On the basis of ritual in its own right, I argued that the butchers are analogues of the border between exterior and interior, the border thereby stretched into the farmstead, into the pigsty, into the pig, into the corpse, into the home, turning outside into inside, emerging through the pig's interior as the power of sexuality and procreation, penetrating the kitchen, the women's domain, there 
cooked into sustenance that sustains human beings and social relationships. Ritual in its own right identifies a dynamic of curving, of self-closing, forming a fold that itself is a border reorganizing itself with profound consequences for the farmstead. Yet if the butchers are the analogues of a moveable border, what is the pig, given the additional ethnography from the sociocultural surround?

The moveable border that is the butchers meets the pig. Given its cultural attributes, the pig also has qualities of a living border. The pig is something like the stranger, yet positioned deep within the farmstead rather than outside it, perhaps a border between the human and the unhuman, the human and itself, an unhuman other living in close proximity to humans, the distinction between inhuman and human, between selfness and otherness within the farmstead. Yet it is a border to be effaced, if the pig is to die for humans so that they can become more fully human as social and sociable beings. As the head butcher kills the pig, one stranger destroys another, one (exterior) border destroys another (interior) one, opening the farmstead simultaneously from its outside and its inside, enabling numerous guests to move from the exterior to the deeply interior, towards the festive supper, and the pig to move towards becoming food for that repast. The cut up pieces of this interior border (the pig), made into sausage, become the sustenance for a generative, procreative sociality of labor between strange men and household women, extending later in the day to the greater collectivity of the festive supper.

It is this opening of the farmstead-blossoming within the self-organizing space/time of the fold, its participants interacting through the night into the new day through joy, fun, good spirits, and fellowship-that is being birthed. Minnich $(1979,138-140)$ comments that the killing of the pig, of a close associate, is consecrated to a degree and has qualities of sacrifice (191), though there are difficulties in stating this baldly. Sacrifice destroys boundaries in order to create new ones, new forms. Killing the pig-destroying the implicit border, deeply interior within the farmstead, and domesticating this deep interiority that signifies otherness, the unnamed, obscenity, unbridled sexuality, and yet a kind of intimacy-is done by the head butcher, the exterior plane of that other, more explicit border separating the autonomous farmstead from social others. The exterior border destroys the interior border, changing both in the process, so that during the remainder of the fold's time/space, neither border exists. As I commented, the butchers re-entering the home are not the same ones who went out to kill the pig. Now they are more the intimates of the home, their own sexuality and procreative drive more open, especially brought home through ribaldry; and to a degree, the women respond in kind. Butchers and women cooperate in shaping sustenance from the sacrifice.

The corpse of the pig also is changed-blessed before its body parts move into the home. One border destroys the other, destroying itself in the process. Furthermore, this nullifying of borders enables whatever they excluded to flow together and to fill out into fruitful union. The gospodar-who, in his rightful standing as the head of the farmstead, would block these movements-stands down, stands aside, and is implicated neither in the killing nor in the changes 
in relationships within the household. The sustenance formed from the sacrifice has qualities of a sacrament, eaten in various forms during the festive meal by the solidary, though more amorphous, collectivity of kin, neighbors, friends.

This re-embedded analysis may also illuminate why Furez should be practiced before and close to the Catholic Christmas. If the pig is a sacrifice eaten as sacrament by the autonomous farmstead, itself 'reborn' as a broad, solidary community without clear-cut borders and with little internal hierarchy, then in cosmic terms Furez resonates with Christmas as a preparation for the birth of the savior, whose sacrificial death is transformed into sacrament. I am not saying that Furez is an analogue of the birth and death of Christ, but I am saying that through the self-organizing closure of the Furez fold, one is made to resonate with the other. Prior to Christmas, the farmstead takes itself apart from within itself so that it is remade and delimited again, yet differently, by its exteriors turned into interiors. ${ }^{19}$

These interiors become recursive pockets in the curving fold of Furez. That is, Furez itself is a filling-and fillings within fillings-of the space/time opened through self-organization. The farmstead is filled with strangers (the butchers); the pig is filled with itself (the pork mix stuffed into its intestines); the home is filled with people (the guests); the people are filled with pork. The space/time of Furez is filled entirely with its own special mix. These fillings within fillings likely would not occur without the erasure of boundaries, enabling different substances with different values to enter one another. This also is a kind of filling of the world, a bringing of the world into fullness; perhaps echoing practices of All Hallows, All Souls, and All Saints, in the Christian universe, filling the cosmos with an entirety of its presence, awaiting the coming presence of Christ. ${ }^{20}$

\section{Conclusion}

The three instances discussed here begin to show how 'rituals', when treated analytically in their own right, demonstrate varying degrees of interior self-organization and complexity. Degrees of self-organization support the contention that the most complex kind of agency a ritual can have built into its design is that of making radical change through its own interior dynamics. The least complex is for a ritual to be quite continuous with the sociocultural surround, lineally reflecting and representing it in manifold ways of show and tell-telling it stories about itself, showing it to itself from various aspects, magnifying, miniaturizing, upending, celebrating, mourning, and so forth. In the latter instance, the connectivity between ritual and its surround passes through a border that hardly distinguishes, hardly differentiates, between one and the other, since the mandate of such ritual is more that of highlighting, embellishing, enhancing, and condensing than of creating difference and making change. But more complex agency depends upon greater curvature; curvature leads inevitably to selfreference and reification as a relatively autonomous phenomenon or event; and relative autonomy leads to self-organization that activates controlled causality to 
make change. In practice, the causality of curvature is circular (Haken 1993), through which distinctions such as those of 'structure' and 'process' are indivisible, through which structure as process bends through causality into itself, coming out elsewhere, differently, re-formed. Within the complexities of increasing self-organization, causality is not linear.

In the instance of Maria Antonia at the Rhine, her crossing as Marie Antoinette was one of a lineally continuous series of events, each event a module, such that the addition together of the modules constituted the entire passage. One may surmise that though integral to a culture of royal display and elaboration, many of these modules could have been done away with, should geopolitical and other conditions have required it. ${ }^{21}$ The basic movement from Vienna to Versailles, from Maria Antonia to Marie Antoinette, would not have been effected, even if the status and esteem of the royal houses suffered. In the instance of the regiment, moving into dance embodied an explicit dynamic, away from the lineal into curving. The movement into dance immediately shaped some degree of more complex self-organization that sustained itself as distinct from its surround, if only for a short while. Of the three examples, Furez demonstrates that when a program for radical change is integral to ritual design, the ritual will be self-organizing to a high degree and relatively autonomous from its surround. These three instances suggest that studying ritual in its own right may be a useful strategy for thinking on ritual, one quite distinct from those usually encountered in anthropology and cognate disciplines, and in these terms opening towards a more comparative study of the phenomenality of ritual that is committed neither to the pursuit of universal definitions of ritual nor to cultural relativism.

\section{ACKNOWLEDGMENTS}

Versions of this introduction were read to colloquia of the Department of Anthropology, University of Leuven, and the Ritual Dynamics Project of the University of Heidelberg, under the auspices there of the South Asia Institute. My thanks to the participants for their interested and constructive comments.

\section{NOTES}

1. Frits Staal (1996, 131-132) argues that ritual exists "for its own sake," constituting "its own aim or goal." Therefore, ritual does not have meaning within itself, for its own sake, since meaning indexes representation. Our perspectives coincide to an extent, though I reject his speaking for 'ritual' as a generic category, and so, too, his use of any specific ritual, in particular the Vedic agnicayana, as paradigmatic of all ritual. See Malamoud $(2002,25)$ on systemic aspects of the agnicayana. 
2. The phrasing "ritual in its own right" was used by de Boeck and Devisch (1994) to develop a critique of studies of divinatory ritual in Central Africa, particularly those of Victor Turner, in which the dynamics of ritual transformation are reduced, in their words, to a script or text located in social order and not in the ritual moment.

3. The overall perspective resonates to a degree with the call by Castoriades $(1997,339)$ to comprehend social and psychological forms and patterns from within themselves, from the perspective of their "self-constitution."

4. By shifting from the usual discussion of levels of macro/micro-organization to domains of organization, I am assuming that the existence of microdomains, however they are organized, is not predicated on the existence of macrosystems. By beginning analysis with the microdomain of ritual, I enable the relationship between ritual and its (more macro) surround to be guided by the ways in which the ritual is organized, without assuming that this is subordinated to or directly derived from the macro.

5. The reasoning likely depends on Spencer Brown's (1969) logical injunction that once a distinction is made, both sides of the distinction must be included in what follows.

6. Just how embedded lineality is in Western taken-for-granted perceiving and thinking is brilliantly discussed by Lee (1959).

7. On torsion, see Bunn $(1981,16-17)$, who argues that in torsion, or torque, as I use it, there is discontinuity rather than absolute fit in the joining of difference-here, the torquing of ritual into social order.

8. On propensity in form, see Jullien $(1995,75-89)$.

9. Here I sidestep my own position (which I continue to hold) that the idea of ritual is utterly otiose (see Handelman 1998, n.d.a). On the development in Western thought of the phenomenal category of 'ritual,' see Boudewijnse (1995) and Asad (1993).

10. On the significance of 'depth' for recursivity, see Rosen (2004).

11. Erving Goffman $(1981,63)$ wrote of his belief that "the way to study something is to start by taking a shot at treating the matter as a system in its own right ... it is [this] bias which led me to try to treat face-to-face interaction as a domain in its own right ... and to try to rescue the term 'interaction' from the place where the great social psychologists and their avowed followers seemed prepared to leave it."

12. The position for creativity in ritual action during ritual performance is argued by Csordas $(1997,250-265)$.

13. Deleuze's $(1991,58-59,118)$ reading of Bergson moves in this direction. The curve may be said to create past and future simultaneously, folding them into one another, creating short cuts between them.

14. Thus, the greater the self-organizing and self-sustaining capacities of a ritual, the greater the degree of discontinuity in its torquing back into social order. However, if ritual selforganization creates itself as the replacement of social order, so that the ritual is the simulacrum of the basic premises of social order, then there is no discontinuity between the two. The outcome of the ritual returns to its surround $a$ s that surround. Here there is no longer any distinction between the ideal and the real, between map and territory.

15. Unlike the lineal movement of Maria Antonia, the trajectory of the dancers likely moved through a recursive multistability of perspective, of dancers holding onto dancers moving past dancers holding onto dancers who were moving past them. Multistability refers to a fluidity of perception, a multiplicity of perspectives, opening pathways of possibility that nonetheless keep proportional relationships and ratios, thereby exploring variations of propensity within form and sense (see Friedson 1996, 139-144; Ihde 1983).

16. Rousseau's remembering may be called imagistic and episodic (Whitehouse 2000, 9-11, 92-93). The event likely was more a singular than a repetitive episode, though one with powerful, particularistic reverberations for the participants.

17. In the not distant past, Furez was held on three consecutive days, each day given over to one of the three segments. 
18. There is the question, beyond the scope of this work, of whether the folding of a rite deeper and deeper into itself might not generate fractal-like qualities within the phenomenon. Today, this would be my understanding of my reanalysis (Handelman 1979) of Bateson's analysis of naven behavior among the Sepik River Iatmul-the fractal-like relationship between a single utterance that is fully naven behavior, on the one hand, and a complex performance that is fully naven behavior, on the other. Its fractal-like qualities would self-enclose the phenomenon within its own variations, expansions, contractions.

19. This part of the re-embedded analysis may be understood as a modification of Zempleni's $(1990,208)$ argument that "what disintegrates the group periodically on the inside is converted in a force which delimits it continuously from the outside."

20. Might not these 'fillings' be thought of, in relation to one another, as having fractallike qualities?

21. On modularity in ritual organization, see Handelman (n.d.b).

\section{REFERENCES}

Asad, Talal. 1993. Genealogies of Religion: Discipline and Reasons of Power in Christianity and Islam. Baltimore: Johns Hopkins University Press.

Baecker, Dirk. 2001. "Why Systems?” Theory, Culture \& Society 18:59-74.

Bailey, Kenneth D. 1997. “The Autopoiesis of Social Systems: Assessing Luhmann's Theory of Self-Reference." Systems Research and Behavioral Science 14:83-100.

Bateson, Gregory. 1977. "Afterword.” Pp. 235-247 in About Bateson, ed. John Brockman. New York: E. P. Dutton.

Bloch, Maurice. 1992. Prey into Hunter: The Politics of Religious Experience. Cambridge: Cambridge University Press.

Boudewijnse, Barbara. 1995. "The Conceptualization of Ritual: A History of Its Problematic Aspects." Jaarboek voor Liturgie-Onderzoek 11:31-56.

Bunn, James H. 1981. The Dimensionality of Signs, Tools, and Models. Bloomington: Indiana University Press.

Castoriades, Cornelius. 1997. World in Fragments. Stanford: Stanford University Press.

Coppet, Daniel de. 1990. "The Society as an Ultimate Value and the Socio-Cosmic Configuration." Ethnos 55, no. 3/4:140-150.

-_- 1992. "Introduction.” Pp. 1-10 in Understanding Rituals, ed. Daniel de Coppet. London: Routledge.

Csordas, Thomas J. 1997. Language, Charisma, and Creativity: The Ritual Life of a Religious Movement. Berkeley: University of California Press.

Darnton, Robert. 1985. The Great Cat Massacre and Other Episodes of French Cultural History. New York: Vintage Books.

de Boeck, Filip, and Rene Devisch. 1994. "Ndembu, Luunda and Yaka Divination Compared: From Representation and Social Engineering to Embodiment and Worldmaking." Journal of Religion in Africa 23, no. 2:98-133.

Deleuze, Gilles. 1991. Bergsonism. New York: Zone Books.

- - . 1993. The Fold: Leibniz and the Baroque. London: Athlone Press.

Elias, Norbert. 1983. The Court Society. New York: Pantheon Books.

Feld, M. D. 1975. "Middle-Class Society and the Rise of Military Professionalism: The Dutch Army 1589-1609." Armed Forces and Society 1:419-442.

Feyerabend, Paul. 1978. Against Method. London: Verso. 
Foucault, Michel. 1993. "Dream, Imagination and Existence.” Trans. Forrest Williams. Pp. 31-38 in Michel Foucault and Ludwig Binswanger, Dream and Existence, ed. Keith Hoeller. Atlantic Highlands, N.J.: Humanities Press.

Friedson, Steven M. 1996. Dancing Prophets: Musical Experience in Tumbuka Healing. Chicago: University of Chicago Press.

Geertz, Clifford. 1973. The Interpretation of Cultures. New York: Basic Books.

--_. 1980. Negara: The Theatre State in Nineteenth-Century Bali. Princeton, N.J.: Princeton University Press.

Gerholm, Tomas. 1988. “On Ritual: A Postmodernist View.” Ethnos 53:190-203.

Gluckman, Max, ed. 1962. Essays on the Ritual of Social Relations. Manchester: Manchester University Press.

Goffman, Erving. 1961. Encounters: Two Studies in the Sociology of Interaction. Indianapolis: Bobbs-Merrill.

- - . 1981. "A Reply to Denzin and Keller." Contemporary Sociology 10:60-68.

Gurevich, Aaron. 1995. The Origins of European Individualism. Oxford: Blackwell.

Haken, Hermann. 1993. “Are Synergetic Systems (Including Brains) Machines?” Pp. 123-137 in The Machine as Metaphor and Tool, ed. Hermann Haken, Anders Karlqvist, and Uno Svedin. Berlin: Springer-Verlag.

Handelman, Don. 1973. "Gossip in Encounters: The Transmission of Information in a Bounded Social Setting.” Man (n.s.) 8:210-227.

-_- 1977. Work and Play Among the Aged: Interaction, Replication and Emergence in a Jerusalem Setting. Assen: Van Gorcum.

- - - 1979. "Is Naven Ludic? Paradox and the Communication of Identity." Social Analysis 1:177-191.

- - . 1998. Models and Mirrors: Towards an Anthropology of Public Events. 2nd ed. New York: Berghahn Books.

_- - 1999. "The Playful Seductions of Neo-Shamanic Ritual." History of Religions 39:65-72.

- - . 2002. "Postlude: The Interior Sociality of Self-transformation." Pp. 236-253 in Self and Self-transformation in the History of Religions, ed. David Shulman and Guy Stroumsa. New York: Oxford University Press.

- - - n.d.a. "Conceptual Alternatives to Ritual." In Theorizing Ritual, ed. Jens Kreinath, Jan Snoek, and Michael Stausberg. Leiden: Brill. (In press)

- - - n.d.b. "Designs of Ritual: The City Dionysia in Fifth-Century Athens." In Celebrations: Sanctuaries and the Vestiges of Cult Activity. Athens: Norwegian Institute at Athens. (In press)

Haslip, Joan. 1987. Marie Antoinette. London: Weidenfeld and Nicolson.

Hayles, N. Katherine. 1999. How We Became Posthuman: Virtual Bodies in Cybernetics, Literature, and Informatics. Chicago: University of Chicago Press.

Horgan, John. 1998. The End of Science. London: Abacus.

Ihde, Don. 1983. Existential Technics. Albany: State University of New York Press.

Innis, Robert E. 2001. "Perception, Interpretation, and the Signs of Art." Journal of Speculative Philosophy 15:20-33.

Jullien, François. 1995. The Propensity of Things: Towards a History of Efficacy in China. Trans. Janet Lloyd. New York: Zone Books

Kapferer, Bruce. 1997. The Feast of the Sorcerer. Chicago: University of Chicago Press.

Kauffman, Louis H. 1987. "Self-Reference and Recursive Forms." Journal of Social and Biological Structures 10:53-72.

King, Michael, and Chris Thornhill. 2003. "'Will the Real Niklas Luhmann Stand Up, Please.' A Reply to John Mingers." Sociological Review 51:276-285.

Knyazeva, Helena. 2003. "Self-Reflective Synergetics." Systems Research and Behavioral Science 20:53-64.

Lee, Dorothy. 1959. Freedom and Culture. Englewood Cliffs, N.J.: Prentice-Hall. 
Lévi-Strauss, Claude. 1981. The Naked Man. New York: Harper \& Row

Luhmann, Niklas. 1997. "The Control of Intransparency." Systems Research and Behavioral Science 14:359-371.

- - . 1999. "The Paradox of Form.” Pp. 15-26 in Problems of Form, ed. Dirk Baecker. Stanford: Stanford University Press.

Malamoud, Charles. 2002. "A Body Made of Words and Poetic Meters." Pp. 19-28 in Self and Self-Transformation in the History of Religions, ed. David Shulman and Guy G. Stroumsa. New York: Oxford University Press.

Marin, Louis. 1991. "Classical, Baroque: Versailles, or the Architecture of the Prince." Yale French Studies 80:167-182.

McNeil, Donald H. 2004. "What's Going On with the Topology of Recursion?" The SEED Journal 4, no. 1:2-37. http://www.library.utoronto.ca/see/pages/SEED_Journal.html.

McNeill, William H. 1995. Keeping Together in Time: Dance and Drill in Human History. Cambridge, Mass.: Harvard University Press.

Mingers, John. 2002. "Can Social Systems Be Autopoietic? Assessing Luhmann’s Social Theory." Sociological Review 50:278-299.

Minnich, Robert Gary. 1979. The Homemade World of Zagaj: An Interpretation of the "Practical Life" Among Traditional Peasant-Farmers in West Haloze-Slovenia, Yugoslavia. Bergen: Sosialantropologisk Institut, Universitetet I Bergen (Occasional Paper No. 18).

Rosen, Steven M. 2004. "What Is Radical Recursion?" The SEED Journal 4, no. 1:38-57. http://www.library.utoronto.ca/see/pages/SEED_Journal.html.

Rousseau, Jean-Jacques. 1982. Politics and the Arts: Letter to M. D'Alembert on the Theatre. Ithaca, N.Y.: Cornell University Press.

Smith, Pierre. 1982. "Aspects of the Organization of Rites." Pp. 103-128 in Between Myth and Transgression: Structuralist Essays in Religion, History, and Myth. ed. M. Izard and P. Smith. Chicago: University of Chicago Press.

Spencer Brown, G. 1969. Laws of Form. London: Allen and Unwin.

Staal, Frits. 1996. Ritual and Mantras: Rules without Meaning. Delhi: Motilal Banarsidass Sutton-Smith, Brian. 1997. The Ambiguities of Play. Cambridge, Mass.: Harvard University Press.

Turner, Frederick. 1997. "Foreword: Chaos and Social Science." Pp. xi-xxvii in Chaos, Complexity, and Sociology, ed. Raymond A. Eve, Sara Horsfall, and Mary E. Lee. Thousand Oaks, Calif.: Sage.

Whitehouse, Harvey. 2000. Arguments and Icons: Divergent Modes of Religiosity. Oxford: Oxford University Press.

You, Haili. 1994. "Defining Rhythm: Aspects of an Anthropology of Rhythm.” Culture, Medicine and Psychiatry 18:361-384.

Zempleni, Andras. 1990. "How Do Societies and 'Corporate' Groups Delimit Themselves? A Puzzle Common to Social and Medical Anthropology." Culture, Medicine and Psychiatry 14:201-211. 